\title{
Variability of forwarder truckload parameters in the Pryazha forestry division of the Republic of Karelia (Russia): A computer experiment
}

\author{
Pavel Budnik ${ }^{1 *}$, Ilya Shegelman ${ }^{1}, V_{\text {Vacheslav Baklagin }}^{2}$ \\ ${ }^{1}$ Petrozavodsk State University, 33, Lenin Str., Petrozavodsk, Republic of Karelia, Russia \\ ${ }^{2}$ Northern Water Problems Institute of the Karelian Research Centre of the Russian Academy of Sciences, \\ Aleksander Nevsky str., Petrozavodsk, Karelia, Russia
}

\begin{abstract}
The goal of the present research is to analyze parameters of a bundle of logs for various models of forwarders in the Pryazha division of forestry of the Republic of Karelia. The investigated parameters were mass and volume of a bundle of logs, stacking factor of the bundle and the number of wood assortments in the bundle. The following models of forwarders have been investigated: John Deere 1210E, John Deere 1110E, Ponsse Elk, Ponsse Wisent, Amkodor 2661-01, Rottne F13D, Rottne F15D, Rottne F18D. We estimated the parameters of bundles formed from spruce sawlog $6.1 \mathrm{~m}$ long and bundles formed from spruce pulpwood $4 \mathrm{~m}$ long. Data on stem forms from harvester recorders have been collected to assess the parameters of a bundle of logs. Parameters of bundles have been determined based on computer experiment. The experiment consists of the following steps: random selection of the stem from the database; simulation of the cut-to-length process; simulation of log stacking process; calculation of parameters of a bundle of logs. We found that parameters of bundles vary to a quite substantial extent. Average variability of a bundle of logs formed of $6.1 \mathrm{~m}$ long spruce saw $\log$ is $4.5 \mathrm{t}$, variability of the volume is $5.8 \mathrm{~m}^{3}$, and variability of the number of wood assortments in a bundle is $49 \mathrm{pcs}$. For a bundle made up of $4 \mathrm{~m}$ long spruce pulpwood variability of mass is on average $2.8 \mathrm{t}$, that of volume $-2.09 \mathrm{~m}^{3}$, that of the number of wood assortments $-57 \mathrm{pc}$. The presented results can inform transportation of wood on cutting areas, planning timber harvesting, as well as development new logging machines.
\end{abstract}

Key words: simulation study; computer experiment; mass of bundle; volume of bundle; number of logs in a bundle; load capacity

Editor: Tomáš Hlásny

\section{Introduction}

Cut-to-length wood harvesting method has been widely practiced in Europe (Proto et al. 2018a). In Nordic countries, harvesting is mainly performed with fully-mechanized cut-to-length wood harvesting system. (Tufts \& Brinker 1993; Vossbrink \& Horn 2004; Gerasimova \& Sokolov 2014). Such a system includes harvester and forwarder (Talbot et al. 2003; Wang et al. 2005; Cambi et al. 2017; Proto et al. 2018b). Fully-mechanized cut-tolength harvesting system has also become increasingly used in the European North of Russia, in particular, in the Republic of Karelia (Gerasimov et al. 2012). When practicing cut-to-length wood harvesting, operations performed by forwarder are the most labour-consuming and expensive ones (Mousavi 2009). Therefore, it is a timely task to upgrade the design of such machines, increasing their reliability.
There is a great number of publications relating to the study of various aspects of forwarder operation (Proto et al. 2018a). The efficiency of forwarder depends on multiple factors, and the most important one is the distance of transportation. (Sever 1988; Ghaffarian et al. 2007). The productivity of forwarder relies heavily on the parameters of truck load (Nurminen et al. 2006; Proto et al. 2018b). Therefore, increased distance of transportation nfluences the parameters of a bundle of logs (weight, volume, number of wood assortments) on forwarder productivity grows. (Raymond 1989; Tiernan et al. 2004). However, research of bundle parameters has yet received little attention, what can decrease the accuracy and significance of the obtained results.

Productivity of forwarders depends on the number of wood assortments in a bundle, which defines the number of cycles of a loader during load and discharge (Tufts and 
Brinker 1993; Tufts 1997; Manner et al. 2013). Minette et al. (2004) point that collection and discharge of logs consume most of the process cycle time of the forwarder operation. The negative impact of the forwarder on the soil is determined by the truck load parameters (Labelle \& Jaeger 2019; Sirén et al. 2019). Many publications deal with ecological aspects, in particular, fuel consumption rate, energy efficiency and exhaust emission (Klvac et al. 2012; Lijewski et al. 2017). Fuel consumption rate and, consequently, exhaust emission depend on the parameters of a bundle of logs.

Research of the parameters of forwarder's bundle is important in order to assess terrain crossing capacity (Voinash \& Vonash 2011) and to ensure machine design reliability (Golyakevich \& Goronovskii 2017). Overloading of the machine negatively affects running gear parts and leads to their premature failure.

Therefore, the assessment of parameters of a bundle of logs to be transported is an important task related to various aspects of forwarder's operation. The solution of this problem will allow logging enterprises to increase the efficiency of logging management. In addition, for manufacturers of logging equipment, this will allow to choose the optimal combination of transmission parameters and components of the running gear parts for certain operating conditions.

The aim of this study was to analyze the parameters of a bundle of logs for various models of forwarders in the Pryazha division of forestry of the Republic of Karelia. In the study, analysis of the parameters of a bundle of logs was performed by using computer experiment. The objective was to assess the variability of mass and volume of a bundle of logs, stacking factor of the bundle and the number of wood assortments in the bundle. The additional objective was to establish the relationship between load area cross section of a forwarder and parameters of a bundle of logs. We have also compared load capacities of considered forwarders with simulated loaded bundle mass values to determine compliance of their load capacity with operating conditions.

\section{Materials and methods}

\subsection{Study region}

This research was conducted in the Pryazha division of forestry of the Republic of Karelia situated in the north of the European part of Russia (Fig. 1). The republic borders with Finland in the west and by the White Sea in the north-east. Pryazha division of forestry is located in the southern part of the Republic of Karelia between Lake Ladoga and Lake Onega. Total estimated timber volume in the Republic of Karelia is $980 \mathrm{mln} . \mathrm{m}^{3}$ including Pryazha division of forestry where timber volume is $58 \mathrm{mln} . \mathrm{m}^{3}$. In the Republic of Karelia, the volume of mature and old growth forests, where harvesting operations are mainly performed, is $289 \mathrm{mln} . \mathrm{m}^{3}$. The volume of mature and old growth forests is $10 \mathrm{mln} . \mathrm{m}^{3}$ in the Pryazha division of forestry. Felling volume in Karelia is $8.2 \mathrm{mln} \mathrm{m}^{3}$ with $11.5 \mathrm{mln} \mathrm{m}^{3}$ of annual allowable cut. In the Pryazha division of forestry the forestry is characterized by the largest extent of annual allowable cut $-82 \%$ of max allowed cut. Actual felling volume is 665 thous $\mathrm{m}^{3}$. The road network for logging of the Pryazha division of forestry is one of the most developed in the Republic of Karelia. In the Pryazha division of forestry average volume of stem is $0.198 \mathrm{~m}^{3}$ and average timber volume is $132 \mathrm{~m}^{3} \mathrm{ha}^{-1}$. Forest taxation data of the areas from which the material has been accumulated, are typical for southern part of Karelia.

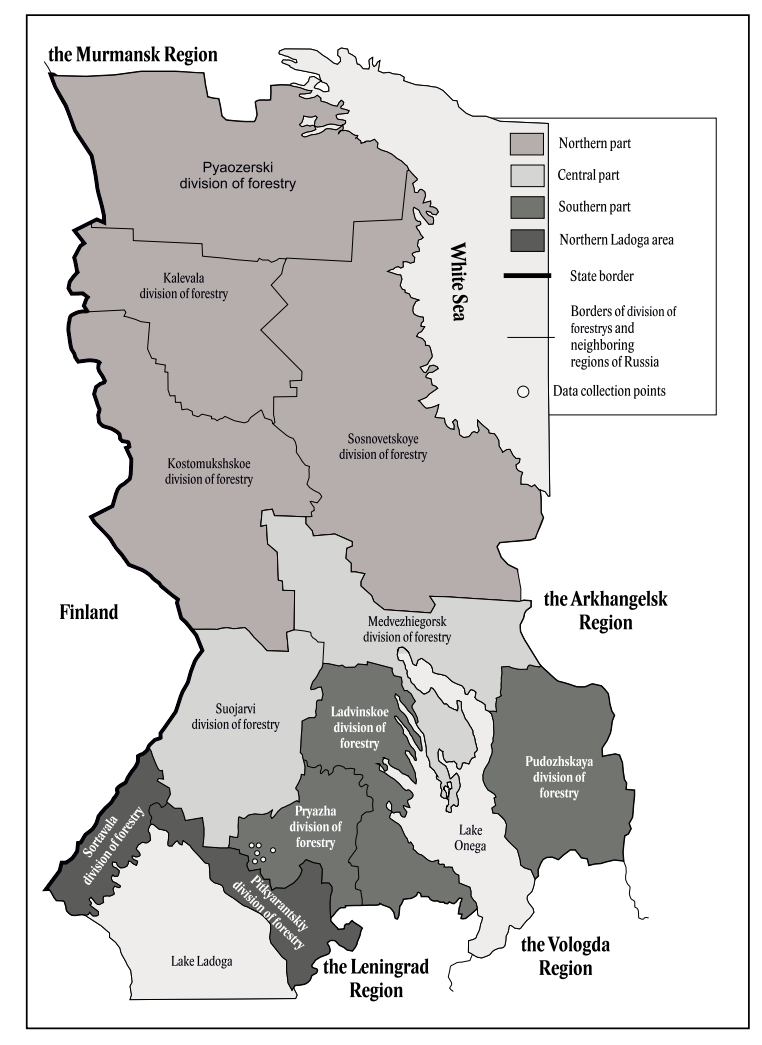

Fig. 1. Map of the Republic of Karelia and the location of sites, where data from forest forwarders were collected.

\subsection{Material}

In order to assess the parameters of a bundle of logs, data on stem forms have been collected. The data have been collected in the Western part of Pryazha division of forestry where logging is most intensive (Fig. 1). Records downloaded from harvester computers have been the source data in this study. These files contained the data about the processed stems in the cutting areas located in the study region. The data included tree species, stem length (length tree without tip), stem volume, diameter values every $10 \mathrm{~cm}$ of stem length. We have collected the data about 53911 stems. Based on the data, a database was formed. The results of statistical processing of the data contained in the database are shown in Fig 2. 


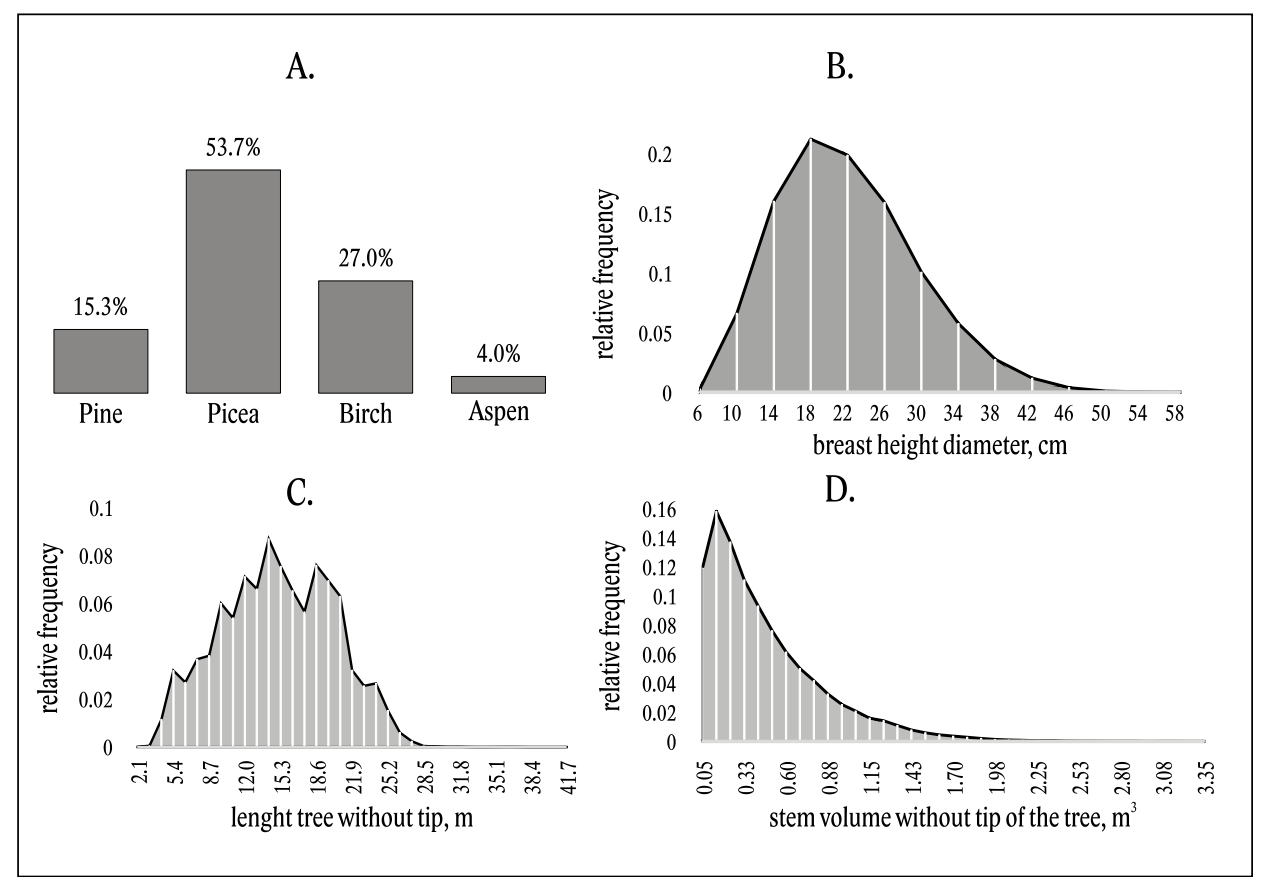

Fig. 2. Statistical characteristics of the collected data. A is distribution of stems by species, B is distribution of stems by breast height diameter, $\mathrm{C}$ is distribution of stems by height, $\mathrm{D}$ is distribution of stems by volume.

\subsection{Investigated machines}

We investigate a broad range of machine type which enable robust inferences and are relevant for the Republic of Karelia. Table 1 gives the technical characteristics of the evaluated machines.

Table 1. Specifications of the evaluated models of forwarders.

\begin{tabular}{lcc}
\hline Name of model & Load capacity $[\mathrm{t}]$ & Load area cross section $\left[\mathrm{m}^{2}\right]$ \\
\hline John Deere 1210E & 13 & 4.0 \\
John Deere 1110E & 12 & 4.0 \\
Ponsse Elk & 13 & 4.5 \\
Ponsse Wisent & 12 & 4.5 \\
Amkodor 2661-01 & 12 & 4.4 \\
Rottne F13D & 14 & 4.7 \\
Rottne F15D & 15 & 4.8 \\
Rottne F18D & 18 & 4.8 \\
\hline
\end{tabular}

\subsection{Methods}

\subsubsection{Study outline}

We estimated the parameters of bundles formed from spruce sawlog $6.1 \mathrm{~m}$ long (No 1) and bundles formed from spruce pulpwood $4 \mathrm{~m}$ long (No 2). Evaluation of variability of parameters of forwarder's bundle of logs requires a great number of measurements (hundreds of measurements per one characteristic). For this reason, we used a computer experiment based on the here developed simulation model.

The simulation model is implemented in form of a program (MS Windows application) using the syntax of C\# language. The process of forming a bundle consisting of the given type of logs has been simulated by means of this model. The following input data have been used for the computer experiment: stem forms properties, parameters of wood assortments to be loaded (species, length, diameter limits in upper and lower cuts); load platform characteristics; loading mode, distance from the protective guard of load area to the nearest woodbunk. The computer experiment has been carried out 10000 times for every combination of the input data.

The experiment consists of the following steps:

1. random selection of the stem from the database;

2. simulation of the simulation of cut-to-length process of the selected stem;

3. simulation of log stacking process;

4. calculation of parameters of a bundle of logs.

Stages 1-3 have been repeated until a bundle was fully loaded, i.e. the forwarder load area was loaded to the height of wodbunks stands.

At the stage 2, the cut-to-length process was simulated, consisting of determining parts of the selected stem satisfying the parameters of the assortment (log No 1 or $\log$ No 2). Assortment parameters were length, limits in lower cut, limits in upper cut. We used different algorithms to simulate of cut-to-length process for log No 1 and $\log$ No 2 . The algorithm for $\log$ No 2 did not allow it to be obtained from butt-log portion. This is due to it is usually not allowed to saw pulpwood from butt-log portion.

The received log (part of the selected stem) has been represented as a number of perfect frustums of cone with 10 or less $\mathrm{cm}$ height for the cones situated on the edges of the log. The number of cones and the diameters of their bases have been the characteristics of the log. The log volume with bark $\left(Q_{l o g}\right.$, mass $\left(M_{l o g}\right)$, diameter in lower $\left(d_{\text {lower }}\right)$ 
and in upper $\left(d_{\text {upper }}\right)$ cut have been calculated on stage 2 . Table 2 defines parameters used during calculation of $Q_{l o g}$ and $M_{l o g}$, and Table 3 - mathematical expressions.

Table 2. Designation of values used during calculation of $Q_{\log }$ and $M_{\text {. }}$.

\begin{tabular}{|c|c|}
\hline Symbol & Explanation \\
\hline $\mathrm{n}$ & number of frustums of cone accounted for log \\
\hline$d_{1, i}$ & diameter of lower base of the $i$-th frustum of cone, for $i=1, n$ \\
\hline$d_{2, i}$ & diameter of upper base of the $i$-th frustum of cone, for $i=1, n$ \\
\hline$h_{\text {. }}$ & height of the $i$-th frustum of cone $\left(h_{i}=10 \mathrm{~cm}\right.$, except for limit \\
\hline & cones in $\log$ for which value $h_{i}$ is defined by interpolation) \\
\hline$Q_{\text {bark }}$ & volume of bark in log \\
\hline$Q_{\text {wood }}$ & log underbark volume \\
\hline$l_{1}$ & $\begin{array}{l}\text { distance from butt of the selected stem to lower base of the first } \\
\text { frustum of cone in log }\end{array}$ \\
\hline$l_{2}$ & $\begin{array}{l}\text { distance from butt of the selected stem to upper base of the last } \\
\text { frustum of cone in log }\end{array}$ \\
\hline$L$ & distance from butt of the selected stem \\
\hline$\rho(L)$ & average density of fresh spruce wood at $L$ distance \\
\hline$\rho_{b}$ & average density of fresh spruce wood bark \\
\hline $\mathrm{k}$ & double thickness of bark \\
\hline$d_{k}$ & diameter over bark \\
\hline$a$ and $b$ & coefficients of linear equation for calculation of $\mathrm{k}$ \\
\hline & moisture content of wood \\
\hline$A, B, C$ and $D$ & coefficients of equation for calculation of $\rho(L)$ value \\
\hline
\end{tabular}

Table 3. Expressions used for calculation of $Q_{\log }$ and $M_{\log }$.

\begin{tabular}{lc}
\hline Equation & $\begin{array}{c}\text { Equation } \\
\text { number }\end{array}$ \\
\hline$Q_{\text {log }}=\sum_{i=1}^{n} \frac{\pi h_{i}\left(d_{1, i}^{2}+d_{1, i} d_{2, i}+d_{2, i}^{2}\right)}{12}$ & {$[1]$} \\
$Q_{\text {bark }}=Q_{\log }-\sum_{i=1}^{n} \frac{\left.\pi h_{i}\left(\left(d_{1, i}-k\right)^{2}+\left(d_{1, i}-k\right)\right)\left(d_{2, i}-k\right)+\left(d_{2, i}-k\right)^{2}\right)}{12}$ & {$[2]$} \\
$Q_{\text {wood }}=Q_{\text {log }}-Q_{\text {bark }}$ & {$[3]$} \\
$M_{\text {log }}=Q_{\text {wood }} \cdot \frac{\int_{l_{1}}^{l_{2}} \rho(L) d L}{l_{2}-l_{1}}+\rho_{b} \cdot Q_{\text {bark }}$ & {$[4]$} \\
$k=a+b d_{k}$ & {$[5]$} \\
$\rho(L)=1.0262 .(1+0.01 W) .\left(A L^{3}+B L^{2}+C L+D\right)$ & {$[6]$} \\
\hline
\end{tabular}

In order to calculate value under expression [5] the following coefficient values were found suitable for the study area $a=0.206$ and $b=0.0356$. Expression [5] and values of coefficients $a, b$ have been taken from state standard GOST 32594-2013 "Roundtimber. Methods of measurements". This standard considers main regulations of European standard EN 1309-2:2006 "Round and sawn timber - Method of measurement of dimensions Part 2: Round timber - Requirements for measurement and volume calculation rules".

Expression [6] comes from the studies of Poluboyarinov (1976), Bogdanov et al. (1981) and Borovikov et al. (1989). Coefficients A, B, C and D for freshlyfelled spruce at average moisture content of $91 \%$ were $0.000105,-0.005,-0.35,380$. Density of bark was set to $1239 \mathrm{~kg} \mathrm{~m}^{-3}$ (Tsyvin 1973).

During stage 4 mass $(M)$ and volume $(Q)$ of fully loaded bundle, number of logs in a fully loaded bundle $(N)$, stacking factor of a fully loaded bundle $\left(K_{q}\right)$ have been determined. Values $M$ and $Q$ have calculated as a sum of values $Q_{\log }$ and $M_{\log }$ of all the logs contained in the formed bundle. Value $K_{q}$ has been determined according to the expression:

$$
K_{q}=\frac{Q}{S_{k} \cdot L}
$$

where $S_{k}$ - load area cross section, $L$ - length of wood assortment.

Forwarder's bundles of logs have been formed from one type of wood assortment. In order to assess the possibility of collecting a bundle of assortments we have introduced a coefficient $K_{p}$ :

$$
K_{p}=N / N_{\text {stem }}
$$

where $N_{\text {stem }}$ is number of generated stems accounted for a bundle of assortments.

\subsubsection{Simulation of log stacking process}

Forwarder load area is a half-frame on which a protective guard and woodbunks are installed (Fig. 3). The volume of logs transported in the load area is defined by the height of the woodbunks stands. Configurations of load area woodbunks of the considered models are shown in Fig. 4.

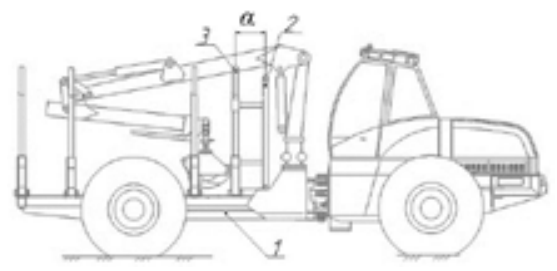

Fig. 3. Forwarder scheme: 1 - half-frame, 2 - protective guard, 3 -woodbunk stand.

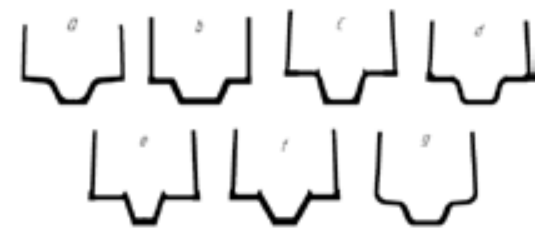

Fig. 4. Shapes of forwarder woodbunks: a - John Deere 1210E and 1110E, b - Amkodor 2661-01, c - Rottne F18D, d - Ponsse Elk, e - Rottne F13D, f - Rottne F15D, g - Ponsse Wisent.

Simulation of the process of log stacking into the load area (stage 3 ) was realized on a 2-dimensional space (Fig. 5). Technically, a woodbunk is represented as an assembly of components characterizing its outer shape as it is shown in Fig. 6. The following elements have been used to describe a woodbunk shape: "wall” (vertical segment); "floor" (horizontal segment); "plane" (inclined segment); "point" (point of joining the elements). Each element has assigned coordinates in a Cartesian coordinate system. Elements were selected so as to best fit the size and shape of the woodbunk. 


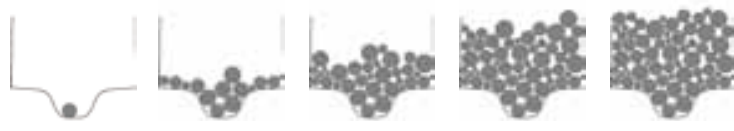

Fig. 5. Graphic display of log stacking process simulation.

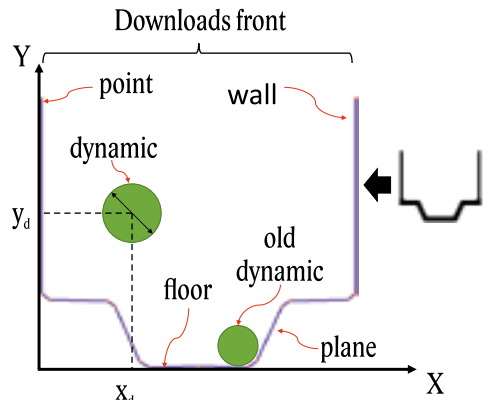

Fig. 6. Woodbunk scheme used in the simulation of log stacking process.

The logs (parts of the selected stems) were represented by their cross sections. The parameters of logs were obtained in stage 2 (simulation of cut-to-length process). We used the cross section of the log at distance $\alpha$ from the log edge (Fig. 3). Value has been defined as a distance from the protective guard to the nearest woodbunk for the respective forwarder model. The value of $\alpha$ was laid either from lower end of the log, or from the top. We alternated the log edge. However, for logs obtained from one stem, the edge did not alternate.

Log has been represented by a "dynamic" element and marked by the center coordinates $\left(x_{d}, x_{d}\right)$, diameter $\left(d_{d}\right)$ and circumference defined as $\left(x-x_{d}\right)^{2}+\left(y-y_{d}\right)^{2}=$ $\mathrm{d}_{\mathrm{d}}^{2} / 4$. Characteristic $d_{d}$ has been defined by the cross section diameter of log situated at the given distance from its edge $(\alpha)$.

Simulation of log stacking process has involved log cross section ("dynamic" element) move within the woodbunk representation layout. Loading has been simulated piece by piece. We used the algorithm which ensured balanced load of the woodbunk layout. Simulation has been carried out with step $\Delta y=1 \mathrm{~mm}$. To describe the interaction of elements, we used the equations obtained on the basis of analytical geometry and laws of theoretical mechanics. These equations characterized three types of interaction of an "dynamic" element with system elements (elements describing woodbunk shape and "old dynamic" elements): collision condition, separation condition, equilibrium condition.

The collision condition was to check for availability of common points between "dynamic" element and other elements. On each simulation step the collision conditions have been checked in the following consequence: "floor", "point”, "plane”, "old dynamic". If the collision condition was fulfilled, then the "dynamic" element moved along the element it encountered with step $\Delta y$. Otherwise, the element "dynamic" moved along the $y-$ axis.
The separation condition was to check for the loss of common points between the "dynamic" element and the other element. If the separation condition was satisfied, but the interaction condition not, then the "dynamic" element moved along the $y$ axis. The equilibrium condition was test of the possibility of movement of the "dynamic" element in its interaction with more than one system element. Here we considered constraining forces on the "dynamic" element and used laws of theoretical mechanics.

\subsubsection{Data analysis}

The result of the computer experiment were values of mass $(M)$ and volume $(Q)$ of a fully loaded bundle of logs, stacking factor of the fully loaded bundle $\left(K_{q}\right)$ and the number of wood assortments in the fully loaded bundle $(N)$ for investigated forwarders. Computer experiment data were statistically processed. We estimated mean observation, minimum value, maximum value and sample range. Frequency distribution curves and cumulative distribution functions $(F(M))$ for each value have been constructed. Values $M$ which with probability 0.9 and 0.99 will not be exceeded (value $M$ at $F(M)=0.9$ and 0.99 ) were determined based on the cumulative distribution functions. Additionally, we determined arithmetic mean values of $M, Q, N$ between all the forwarders for 4, 4.2, $4.5,4.7,4.8 \mathrm{~m}^{2}$ load area cross sections.

Variability of $M, Q, N, K_{q}$ values was estimated by analysis of mean observations, sample ranges and frequency distribution curves. To determine compliance of load capacity the considered forwarder models with operating conditions, comparison of mean observation, maximum value, minimum value of mass, mass at $F(M)$ $=0.9$ and 0.99 with load capacity was carried out. To establish the relationship between load area cross section of a forwarder and parameters of a bundle of logs, we achieved analytical models using the arithmetic mean values of $M, Q, N$. The analytical models are based on classical least squares.

\section{Results}

\subsection{Variability of fully loaded bundle characteristics}

Table 4 contains mean, minimum and maximum values of a fully loaded bundle of logs $(M)$ derived from simulated data. Sample range is $4.0-5.7 \mathrm{t}$ for the bundles made of logs of type No 1; 4.5 t on average for all the considered models. For the bundles formed from the logs of type No 2, sample range is $1.4-1.8 \mathrm{t}$ (1.6t on average). Average value of mass of a bundle formed from the logs of type No 1 is 1.5 times greater than that of a bundle made of the logs of type No.2. Depending on the model of forwarder, the variability of mass of a bundle formed from 
logs of type No 1 has been 2.3 - 3.4 times (on average 2.8 times) larger than the variability of mass of a bundle formed from the logs of type No 2.

Table 5 contains mean, minimum and maximum values of a fully loaded bundle of $\operatorname{logs}(Q)$ derived from simulated data. For the bundle of logs formed from the logs of type No 1 samples range has been within $5.2-7.4 \mathrm{~m}^{3}$ $\left(5.85 \mathrm{~m}^{3}\right.$ on average, in respect to all the considered models). For the bundles formed from logs of type No 2, samples range has been within the interval of $1.9-2.3 \mathrm{~m}^{3}$ $\left(2.09 \mathrm{~m}^{3}\right.$ on average). For all the studied forwarder models the average volume value of a bundle formed from logs of type No 1 is 1.5 times higher than the average volume value of a bundle formed from logs of type No 2 . The variability of volume of bundle formed from logs of type No 1 has been larger than the variability of volume of bundle formed from wood assortments of type No 2, for all the considered forwarder models - by $2.3-3.4$ times (by 2.8 times on average).

Table 6 provides the mean observations, the minimum values, the maximum values of the wood assortments number of a fully loaded bundle $(N)$ derived from simulated data. For bundles of logs formed from logs of type No 1 sample range has been within $46-51$ pcs (49 pcs on average for all the studied models). For bundles made up of wood logs of type No 2, sample range has been within the interval $52-62$ pcs ( 57 pcs on average). Average assortments number of a bundle formed from logs of type No 2 is 2.1 times higher than average assortments number of a bundle made up of logs of type No 1 for all the models of forwarders. Variability of assortments number in a bundle formed from logs of type No 2 has been 1.0 - 1.3 times greater (1.8 times on average), of the variability in a bundle formed from logs of type No 1 for all the studied models of forwarder.

The mean observations, the minimum values, the maximum values of stacking factor of the fully loaded bundle $\left(K_{q}\right)$, obtained on the basis of simulation, are presented in Table 7. For bundles of logs made up logs of type No 1 the sample range has been within $0.20-0.25(0.21$ on average for all the considered models). For bundles formed from logs of type No 2, sample range has been within $0.10-0.12$ pcs ( 0.11 on average). In the mean, the difference in value between bundles formed from logs

Table 4. Variability of fully loaded bundle mass.

\begin{tabular}{|c|c|c|c|c|c|c|c|c|}
\hline \multirow{2}{*}{ Forwarder models } & \multirow{2}{*}{$\begin{array}{c}\text { Load area cross section } \\
{\left[\mathrm{m}^{2}\right]}\end{array}$} & \multirow{2}{*}{ Load capacity [ton] } & \multicolumn{3}{|c|}{$M$ for No 2 [ton] } & \multicolumn{3}{|c|}{$M$ for No 1 [ton] } \\
\hline & & & $\min$ & mean & $\max$ & $\min$ & mean & $\max$ \\
\hline John Deere 1210E/1110E & 4 & $13 / 12$ & 9.36 & 10.13 & 10.86 & 13.00 & 15.09 & 17.13 \\
\hline Amkodor 2661-01 & 4.4 & 12 & 10.22 & 11.07 & 11.89 & 14.21 & 16.48 & 18.76 \\
\hline Ponsse Elk & 4.5 & 13 & 10.42 & 11.21 & 11.96 & 14.20 & 16.69 & 18.68 \\
\hline Ponsse Wisent & 4.5 & 12 & 10.42 & 11.32 & 12.18 & 14.97 & 16.86 & 19.08 \\
\hline ROTTNE F13D & 4.7 & 14 & 10.95 & 11.71 & 12.46 & 15.01 & 17.43 & 19.41 \\
\hline ROTTNE F15D & 4.8 & 15 & 10.97 & 11.90 & 12.66 & 14.71 & 17.75 & 20.38 \\
\hline ROTTNE F18D & 4.8 & 18 & 11.10 & 11.92 & 12.73 & 15.54 & 17.73 & 19.61 \\
\hline
\end{tabular}

Table 5. Variability of fully loaded bundle volume.

\begin{tabular}{|c|c|c|c|c|c|c|c|}
\hline \multirow{3}{*}{ Forwarder models } & \multirow{3}{*}{ Load area cross section $\left[\mathrm{m}^{2}\right]$} & \multicolumn{3}{|c|}{$Q$ for No 2} & \multicolumn{3}{|c|}{$Q$ for No 1} \\
\hline & & \multicolumn{6}{|c|}{$\left[\mathrm{m}^{3}\right]$} \\
\hline & & $\min$ & mean & $\max$ & $\min$ & mean & $\max$ \\
\hline John Deere 1210E/1110E & 4 & 12.15 & 13.15 & 14.10 & 16.91 & 19.63 & 22.28 \\
\hline Amkodor 2661-01 & 4,4 & 13.26 & 14.37 & 15.43 & 18.49 & 21.44 & 24.41 \\
\hline Ponsse Elk & 4,5 & 13.53 & 14.56 & 15.53 & 18.48 & 21.71 & 24.29 \\
\hline Ponsse Wisent & 4,5 & 13.54 & 14.69 & 15.80 & 19.47 & 21.93 & 24.86 \\
\hline ROTTNE F13D & 4,7 & 14.21 & 15.20 & 16.17 & 19.50 & 22.67 & 25.27 \\
\hline ROTTNE F15D & 4,8 & 14.26 & 15.45 & 16.42 & 19.14 & 23.08 & 26.52 \\
\hline ROTTNE F18D & 4,8 & 14.41 & 15.47 & 16.52 & 20.22 & 23.06 & 25.51 \\
\hline
\end{tabular}

Table 6. Variability of wood assortments number of a fully loaded bundle.

\begin{tabular}{|c|c|c|c|c|c|c|c|}
\hline \multirow{2}{*}{ Forwarder models } & \multirow{2}{*}{ Load area cross section $\left[\mathrm{m}^{2}\right]$} & \multicolumn{3}{|c|}{$\mathrm{N}$ for No 2 [pcs] } & \multicolumn{3}{|c|}{$Q$ for No $1[\mathrm{pcs}]$} \\
\hline & & $\min$ & mean & $\max$ & $\min$ & mean & $\max$ \\
\hline John Deere 1210E/1110E & 4 & 138 & 163 & 192 & 52 & 78 & 98 \\
\hline Amkodor 2661-01 & 4,4 & 155 & 178 & 207 & 60 & 85 & 106 \\
\hline Ponsse Elk & 4,5 & 154 & 180 & 214 & 62 & 86 & 112 \\
\hline Ponsse Wisent & 4,5 & 156 & 182 & 209 & 59 & 87 & 109 \\
\hline ROTTNE F13D & 4,7 & 161 & 189 & 223 & 64 & 90 & 112 \\
\hline ROTTNE F15D & 4,8 & 162 & 192 & 221 & 65 & 91 & 114 \\
\hline ROTTNE F18D & 4,8 & 159 & 192 & 220 & 62 & 91 & 113 \\
\hline
\end{tabular}

Table 7. Variability of stacking factor of the fully loaded bundle.

\begin{tabular}{|c|c|c|c|c|c|c|c|}
\hline \multirow{2}{*}{ Forwarder models } & \multirow{2}{*}{ Load area cross section $\left[\mathrm{m}^{2}\right]$} & \multicolumn{3}{|c|}{$K_{q}$ for No $2[\mathrm{pcs}]$} & \multicolumn{3}{|c|}{$K_{q}$ for No $1[\mathrm{pcs}]$} \\
\hline & & $\min$ & mean & $\max$ & $\min$ & mean & $\max$ \\
\hline John Deere 1210E/1110E & 4 & 0.737 & 0.797 & 0.855 & 0.675 & 0.784 & 0.890 \\
\hline Amkodor 2661-01 & 4.4 & 0.742 & 0.804 & 0.863 & 0.681 & 0.790 & 0.899 \\
\hline Ponsse Elk & 4.5 & 0.738 & 0.794 & 0.847 & 0.664 & 0.780 & 0.873 \\
\hline Ponsse Wisent & 4.5 & 0.732 & 0.794 & 0.854 & 0.693 & 0.781 & 0.885 \\
\hline ROTTNE F13D & 4.7 & 0.743 & 0.795 & 0.846 & 0.672 & 0.781 & 0.871 \\
\hline ROTTNE F15D & 4.8 & 0.735 & 0.796 & 0.846 & 0.649 & 0.783 & 0.900 \\
\hline ROTTNE F18D & 4.8 & 0.737 & 0.791 & 0.845 & 0.681 & 0.777 & 0.859 \\
\hline
\end{tabular}


of type No 1 and bundles made up logs of type No 2 is minor and equal to 0.014 . Variability of value for bundles formed from logs of type No 1 has been on average 2 times greater than in bundles formed from logs of type No 2 for all the considered models of forwarders.

Coefficient $K_{p}$ value for a bundle formed from type No 1 logs has been varied between $0.27-0.91$ ( 0.46 on average). For a bundle made up of No 2 type logs, $K_{p}$ coefficient has averagely been 0.98 varied between $0.66-1.44$.

We showed here that with forwarder load area cross section of $4 \mathrm{~m}^{2}$ mass of a fully loaded bundle of logs formed from $6.1 \mathrm{~m}$ long spruce sawlog is on average $15.09 \mathrm{t}$, volume $-19.63 \mathrm{~m}^{3}$, number of wood assortments in a bundle -78 pcs. With forwarder load area cross section of $4.8 \mathrm{~m}^{2}$ mass of a bundle is on average $17.74 \mathrm{t}$, volume $-23.07 \mathrm{~m}^{3}$, number of wood assortments in a bundle- 91 pcs. With forwarder load area cross section of $4 \mathrm{~m}^{2}$ mass of a bundle formed from $4 \mathrm{~m}$ long spruce pulpwood is on average $10.13 \mathrm{t}$, volume $-13.15 \mathrm{~m}^{3}$, number of wood assortments in a bundle -163 pcs. When increasing forwarder load area cross section up to $4.8 \mathrm{~m}^{2}$ mass of a bundle is on average $11.91 \mathrm{t}$, volume $-15.46 \mathrm{~m}^{3}$, number of wood assortments in a bundle- 192 pcs.

In the mean mass of a bundle formed from $6.1 \mathrm{~m}$ long spruce sawlog and its volume is 1.5 times greater than the respective parameters of a bundle formed from $4 \mathrm{~m}$ long spruce pulpwood. Number of wood assortments in a fully loaded bundle made up of $4 \mathrm{~m}$ spruce pulpwood is on average 2.1 times greater than number of assortments in a bundle from $6.1 \mathrm{~m}$ long spruce sawlog.
Average variability of a bundle of logs formed from $6.1 \mathrm{~m}$ long spruce sawlog is $4.5 \mathrm{t}$, that of volume $5.8 \mathrm{~m}^{3}$, and that of the number of wood assortments in a bundle $49 \mathrm{pcs}$. For a bundle made up of $4 \mathrm{~m}$ long spruce pulpwood variability of mass is on average $2.8 \mathrm{t}$, that of volume $-2.09 \mathrm{~m}^{3}$, that of the number of wood assortments -57 pc. On a practical level such significant variability of the truck load parameters is supposed to cause fluctuation of the machine's productivity. Besides, it indicates the irregularity of loads the machine experiences during operation.

The results illustrates that stacking factor depends almost not at all on load area cross section. In addition to it, in the mean difference between the values of stacking factor for a bundle made of $6.1 \mathrm{~m}$ long spruce sawlog and for a bundle formed from $4 \mathrm{~m}$ long spruce pulpwood is minor and equal to 0.014 . Averagely stacking factor for a bundle made up of $6.1 \mathrm{~m}$ long spruce sawlog is 0.782 , and for $4 \mathrm{~m}$ long spruce pulpwood -0.796 .

Fig. 7 shows frequency distribution curves of masses of bundles for the investigated forwarder models obtained on the basis of simulation. The frequency distribution curves are roughly symmetrical and unimodal. Increase of load area cross section has resulted in shifting the variation curve to the right (Fig 7A, 7C). Shape of the frequency distribution curves of different forwarder models with similar values of load space cross section has been differed (Fig. 7B, 7D). Frequency distribution curves for $Q$ and $N$ values have been similar to the frequency distribution curves for $M$ value.

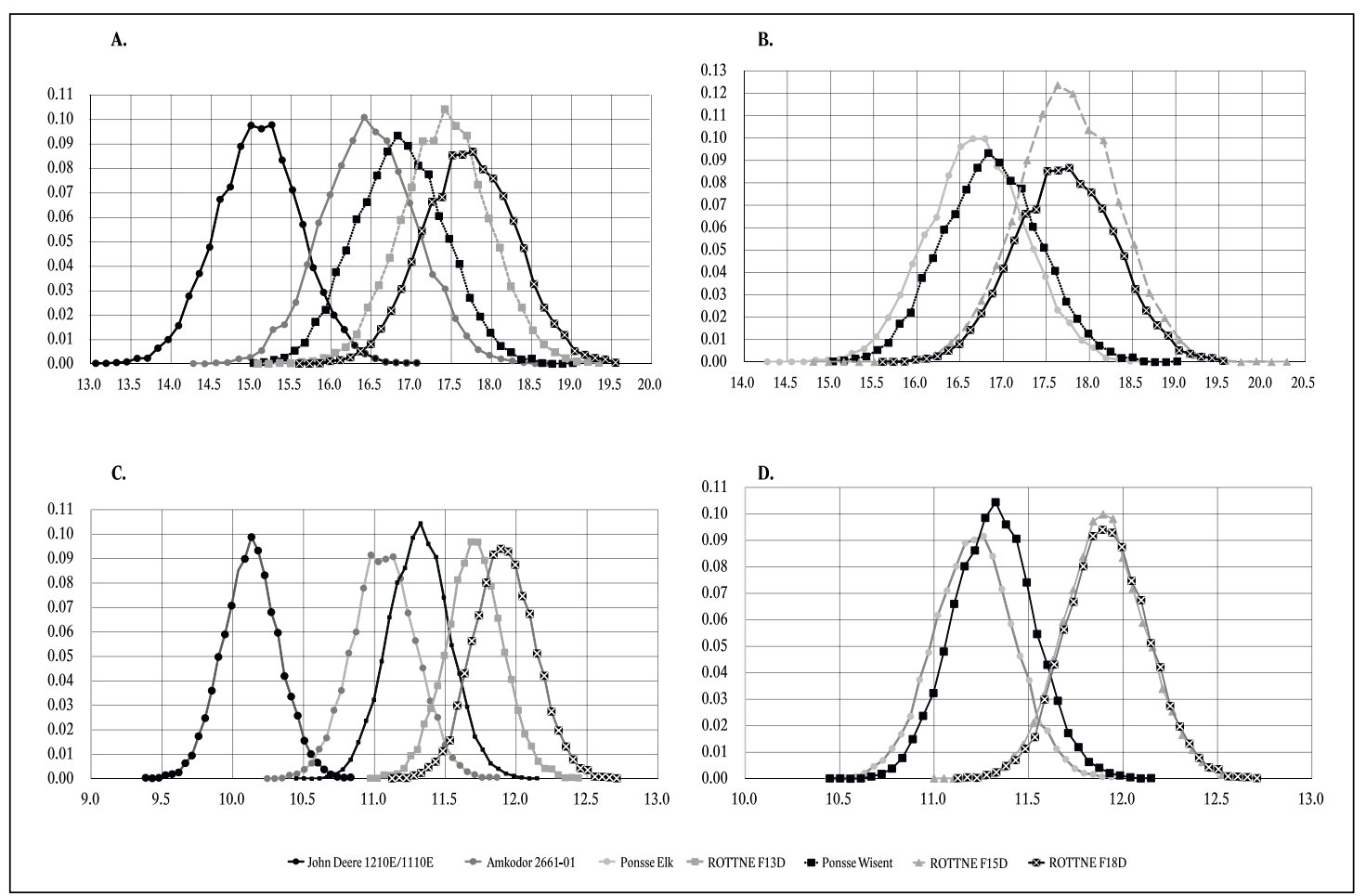

Fig. 7. Frequency distribution curves of $M$ value for the considered models of forwarders, where A, B are bundles formed from logs of type No 1, C, D are bundles formed from logs of type No 2. X-axis is mass of fully loaded bundle. Y-axis is relative frequency. 


\subsection{Comparison of load capacity forwarders with simulated fully loaded bundle mass values}

Fig. 8 presents the results of comparison of load capacity values of the investigated forwarder models with minimum, maximum values of the simulated samples for $M$ value. Values of mass of bundles of $\operatorname{logs}$ with $F(M)=$ 0.9 and $F(M)=0.99$ are shown as well. For the bundles formed from the logs of type No 1, load capacity values have been less than minimumvalue of the samples, except for models Rottne F15D, Rottne F18D (Fig. 7A). For the bundles formed from the logs of type No 2 load capacity values have exceeded maximum values of the samples for all the considered forwarder models. (Fig. 7B). 3.3. Influence of load area cross section on average fully loaded bundle parameters

Dependences of mean volume of a bundle of logs, mean mass of a bundle and average number in a bundle from forwarder load area cross section have been of linear type (Fig. 9). We showed here that the parameters $(M, Q, N)$ of fully loaded bundle formed from $6.1 \mathrm{~m}$ long spruce sawlog change greater than the parameters of fully loaded bundle formed from $4 \mathrm{~m}$ long spruce pulpwood with the same change of load area cross section.

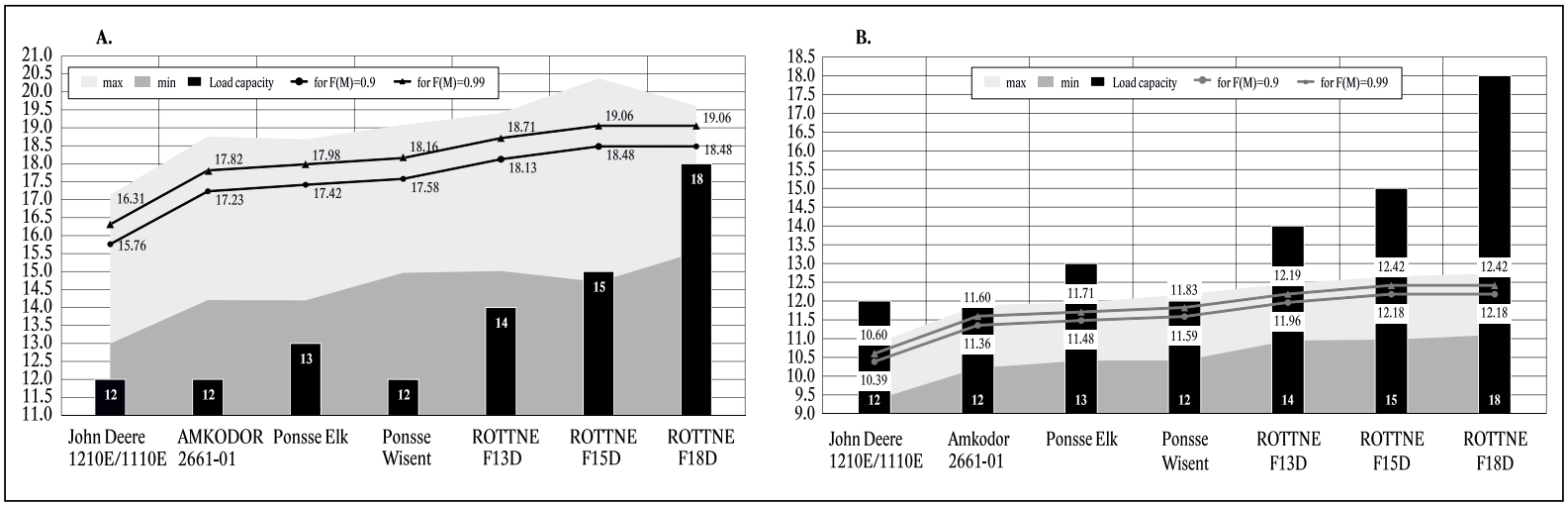

Fig. 8. Comparison of forwarder load capacity with maximum value of simulated fully loaded bundle mass, minimum value, simulated mass at $F(M)=0.9$ and $0.99(F(M)$ - cumulative distribution functions): A - bundles formed from the logs of type No $1, \mathrm{~B}$ - bundles formed from the logs of type No 2.

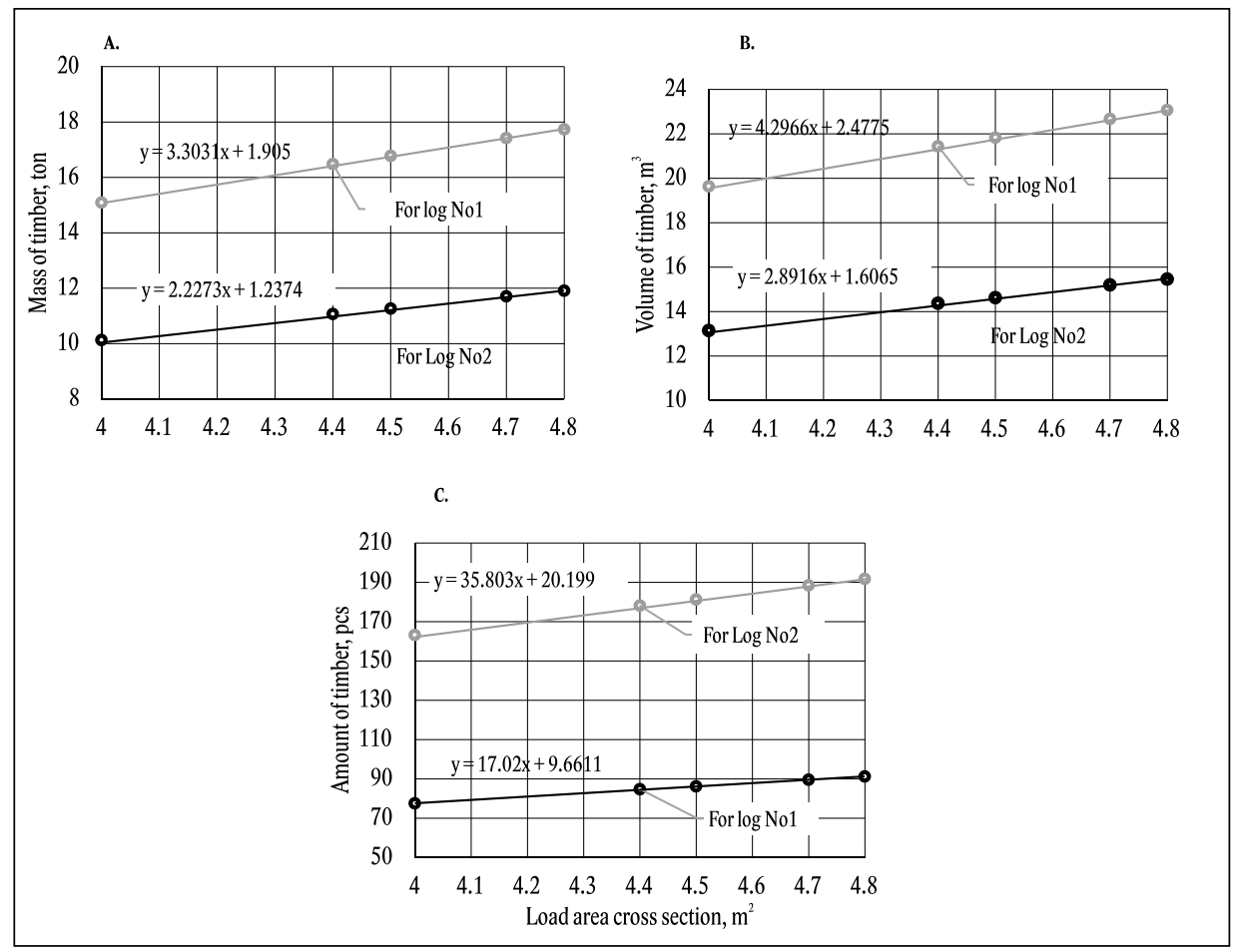

Fig. 9. Dependence of average parameters of a bundle of logs from load area cross section: A - for $M$ value, B - for $Q$ value, $C$ for $N$ value. 


\section{Discussion}

\subsection{Agreement between simulated and observed load capacity values}

Comparison of forwarder load capacities and results of the computer experiment showed that all the studied models of forwarders have sufficient load capacity to transport a bundle formed from $4 \mathrm{~m}$ long spruce pulpwood. However, forwarders Amkodor 2661-01 and Ponsse Wisent showed poorer performance in this regard.

The limitation of this study is that all the calculations have been carried out for spruce wood. The density of spruce is less than that of pine, birch or aspen; and the density of fresh wood during the wettest season can increase (Poluboyarin 1976). Therefore, mass of a bundle, when transporting wood assortments of other species, can exceed the values obtained during the computer experiment.

All the considered forwarder models have insufficient load capacity to transport a fully loaded bundle formed from $6.1 \mathrm{~m}$ long spruce sawlog. Even minimum value of mass of a bundle under the received samples is higher than the load capacity of most of the studied models. Such bundles are always transported due to safety margin of a construction. The results indicate considerable variability of parameters of a fully loaded bundle of logs in the investigated dataset, as well as of insufficient load capacity of the studied forwarder models during transportation of a fully loaded bundle made up of $6 \mathrm{~m}$ long logs.

\subsection{Effect of forwarder woodbunk shape on bundle characteristics}

The obtained results have not allowed drawing a firm conclusion about the influence of load area woodbunks shape on the parameters of a bundle of logs. On the one hand, the results indicate that load area woodbunks shape does little for the average characteristics. On the other hand, differences in shapes of frequency distribution curves for forwarder models with similar load area cross sections point to the fact that woodbunks shape can have certain influence. This indicates that for certain forest stems there is a shape of woodbunks that allows decreasing to some extent the irregularity of parameters of a fully loaded bundle of logs.

\subsection{Modeling uncertainty}

The received evidences about variability of bundle parameters agree quite well with results of the researches conducted in other regions of Europe (Danilović et al. 2014; Pandur et al. 2015; Proto et al. 2018a, 2018b). The results do not contradict the studies earlier performed in the Republic of Karelia. For instance, Katarov et al. (2012) investigated the influence of Ponsse Elk forwarder on soil in Medvezhiegorsk division of forestry were conducted.
The authors recorded the average mass of truck load of $13 \mathrm{t}$. Our studies have shown that on average mass of a fully loaded bundles formed from $4 \mathrm{~m}$ long logs is $11.2 \mathrm{t}$, and those formed from $6.1 \mathrm{~m}$ long $-16.7 \mathrm{t}$. In general, average parameters of a fully loaded bundle according to the results of our researches are comparable to the values recorded by the researches done in other regions (Slamka \& Radocha 2010; Manner et al. 2013; Danilović et al. 2014; Pandur et al. 2015; Petaja et al. 2018; Proto et al. 2018a, 2018b).

The proposed simulation model has some disadvantages. First, simulation of logs loading were conducted in a 2-D space. Therefore, curvature of logs, various flaws, knots, as well as physics of interaction of logs along the overall length, influencing final position of log in load area, are not considered. This may leads to the overestimation of the calculated parameters of a bundle of logs.

Second, the model does not consider forces of inertia and gravity, which provoke additional compaction of logs in forwarder load area and the increase of bundle's stacking factor.

Stem forms in the research have been based on the harvesters' recorders data. Therefore, the third reason of the calculation uncertainties is related to measurements errors of harvesters' recorders. For example, the requirements in Finland stipulate that the measurement error shall be within $\pm 4 \%$ (Nieuwenhuis \& Dooley 2006). However, with proper calibration the present day harvesters' measurement systems can ensure accuracy within $\pm 2 \%$ (Gingras 1995). The researches conducted in Ireland indicate that measurement accuracy is mainly within $\pm 5 \%$, however, cases when the accuracy was beyond \pm $7 \%$ have been registered (Nieuwenhuis \& Dooley 2006). In Russia regulatory documents allow measurement deviations and errors when determining round timber volumes within $\pm 5 \%$.

Additional errors in defining parameters of fully loaded bundles based on harvester recorders are related to the specific character of diameter measurement. When measuring the diameter, if its value is greater than the value measured at the previous moment of time, then the value of the previous measurement is to be recorded. It allows neutralizing bumps on the stem and swells in places where knots grow, when defining the volume of log. However, these elements influence stacking factor of a bundle when putting logs into the load area.

The fourth reason of errors in calculations is associated with the determination of density of wood and log bark. The wood density varies not only depending on a tree height, but also on its diameter (Poluboyarinov 1976). Our researches have not taken into account wood density variation depending on diameter. An average value on a respective tree height has been used. Besides, density depends on moisture content of wood that can vary greatly depending not only on the period of time, but also on the place, where a tree grows in forest stand. We have used average moisture content of fresh wood as a reference in our studies. We have not taken into account 
variation of bark density as per stem length. An average value has been used.

The fifth reason is caused by the limitedness of the used the database that is unable to totally describe the whole variety of stem shapes of the trees on the territory under consideration.

\subsection{Territorial applicability of results}

Purpose of the research has been to assess the parameters of a bundle of wood assortments for Pryazha division of forestry of the Republic of Karelia. The results mostly describe the conditions of southern part of the Republic of Karelia (Fig. 1). For northern part of Karelia it can be expected that the obtained values for the parameters of bundles of logs would be in some way greater than those actually observed. It can be explained by the fact that the trees in the stands of northern part are smaller in size than in Pryazha division of forestry. The trees in the stands of Northern Ladoga area are bigger in size than in Pryazha division of forestry. This suggests that the parameters of bundles of logs received during from the computer experiment would, probably, be less than the actual ones for the conditions of Northern Ladoga area.

\section{Conclusion}

The research has presented the results of the evaluation of parameters of fully loaded bundles of logs from Pryazha division of forestry of the Republic of Karelia. This study was based on computer experiment and considerable amount of empirical data on tree stems. The results can be used by forwarder operators, producers of logging machines, harvest planners.

The study has shown substantial variability in the investigated parameters of bundles. The longer the assortments, which form a bundle, the greater the variability of parameters. Load capacity of the all investigated forwarder models, when transporting bundles formed from logs with length above $6 \mathrm{~m}$, is insufficient. We recommend forwarder operators loading the load area by $3 / 4$ at the most, when making up a bundle of $6 \mathrm{~m}$ long assortments. It will reduce the risk of load capacity excess.

For designers of logging machines, we recommend ensuring load capacity of at least $16 \mathrm{t}$ with load area cross section of $4 \mathrm{~m}^{2}$, and with the area of $4.8 \mathrm{~m}^{2}-19 \mathrm{t}$. Intermediate values can be found by interpolation. These values of load capacity do not consider the margin, which is usually $20-30 \%$.

\section{Acknowledgments}

The researches have been performed within the frameworks of implementing grant of the President of the Russian Federation No. MK-5321.2018.8.

\section{References}

Bogdanov, E. I., Kozlov, B. A., Peych, N. N., 1981: Spravočnik po suške drevesiny. Moscow, Forest industry, $192 \mathrm{p}$.

Borovikov, A., M., Ugolev, B., N., 1989: Spravočnik po drevesine. Moscow, Forest industry, 296 p.

Cambi, M., Grigolato, S., Neri, F., Picchio, R., Marchi, E., 2017: Effects of forwarder operation on soil physical characteristics: a case study in the Italian Alps. Croatian Journal of Forest Engineering, 37:233-239.

Danilović, M., Stojnić, D., Karić, S., Sučević, M., 2014: Transport of Technical Roundwood by Forwarder and Tractor Assembly from Poplar Plantations. Nova mehanizacija šumarstva, 35:11-22.

Gerasimov, Y., Senkin, V., Väätäinen, K., 2012: Productivity of single-grip harvesters in clear-cutting operations in the northern European part of Russia. European Journal Forest Research, 131:647-654.

Gerasimova, Y., Sokolov, A., 2014: Ergonomic evaluation and comparison of wood harvesting systems in Northwest Russia. Applied Ergonomics, 45: 318-338.

Ghaffarian, M. R., Stampfer, K., Sessions, J., 2007: Forwarding productivity in Southern Austria. Croatian Journal of Forest Engineering, 28:169-175.

Gingras, J-F., 1995: Recent Developments in Chip Cleaning and Cut-To-Length Harvesting Technologies in Finland. Forest Engineering Research Institute of Canada (FERIC) Eastern Division, Internal Report: IR-1995-06-01.

Golyakevich, S. A., Goronovskii, A. R., 2017: Evaluation of Loading Dynamics and Fatigue Life for a Forwarder Half-Frame Articulation. Journal of Machinery Manufacture and Reliability, 46:52-62.

Klvac, R., Fischer, R., Skoupy, A., 2012: Energy use of and emissions from the operation phase of a medium distance cableway system. Croatian Journal of Forest Engineering, 33:79-88.

Labelle, E. R., Jaeger, D., 2019: Effects of Steel Flexible Tracks on Forwarder Peak Load Distribution: Results from a Prototype Load Test Platform. Croatian Journal of Forest Engineering, 40:1-23.

Lijewski, P., Merkisz, J., Fuć, P., Ziółkowski, A., Rymaniak, L., Kusiak, W., 2017: Fuel consumption and exhaust emissions in the process of mechanized timber extraction and transport. European Journal of Forest Research, 136:153-160.

Manner, J., Nordfjell, T., Lindroos, O., 2013: Effects of the number of assortments and log concentration on time consumption for forwarding. Silva Fennica, 47:1-19.

Minette, L. J., Moreira, F. M. T., De Souza, A. P., Machado, C. C., Silva, K. R., 2004: Análise técnica e econômica do forwarder em três subsistemas de colheita de florestas de eucalipto. RevÁrvore, 28:91-97. 
Mousavi., S. R., 2009: Comparison of productivity, cost and environmental impacts of two harvesting methods in Northern Iran: short-log versus long-log. Ph.D. Thesis. University of Joensuu, Finland.

Nieuwenhuis, M., Dooley, T., 2006: The Effect of Calibration on the Accuracy of Harvester Measurements. International Journal of Forest Engineering, 17: 25-33.

Nurminen, T., Korpunen, H., Uusitalo, J., 2006: Time consumption analysis of the mechanized cut-tolength harvesting system. Silva Fennica, 40:335-363.

Pandur, Z., Horvat, D., Šušnjar, M., Zoric, M., Kneževic, M., 2015: Load space utilization of a Valmet 860.4 forwarder. Proceedings of the 48th FORMEC Symposium 2015 Oct 4 - 8, 2015, Linz, Austria, p. 271275.

Petaja, G., Kaleja, S., Zimelis, A., Lazdins, A., 2018: Comparison of productivity of standard and accumulating forwarder grapple in thinning. Engineering for rural development, p. 1366-1371.

Poluboyarin, O., N., 1976: Plotnost' drevesiny. Moscow, Forest industry, $160 \mathrm{p}$.

Proto, A. R., Macrì, G., Visser, R., Visser, R., Harrill, H., Russo, D. et al., 2018a: A Case Study on the Productivity of Forwarder Extraction in Small-Scale Southern Italian Forests. Small-Scale Forestry, 17:71-87.

Proto, A. R., Macrì, G., Visser, R., Visser, R., Harrill, H., Russo, D. et al., 2018b: Factors affecting forwarder productivity. European Journal Forest Research, 137:143-151.

Raymond, K. A., 1989: Mechanised shortwood thinning with forwarder extraction (Project Report 42). New Zealand Logging Industry Research Association, p. $1-17$.

Sever, S., 1988: Proizvodnost i perfomanse forvardera u radovima privlacenja drva. Mehanizacija Sumarstva, 18:59-87.
Sirén, M., Salmivaara, A., Ala-Ilomäki, J., Launiainen, S., Lindeman, H., Uusitalo, J. et al., 2019: Predicting forwarder rut formation on fine-grained mineral soils. Scandinavian Journal of Forest Research, 34:145-154.

Slamka, M., Radocha, M., 2010: Results of harvesters and forwarders operations in slovakian forests. Lesnícky časopis - Forestry Journal, 56:1-15.

Talbot, B., Nordfjell, T., Suadicani, K., 2003: Assessing the Utility of Two Integrated Harvester-Forwarder Machine Concepts Through Stand-Level Simulation. International Journal of Forest Engineering, 14:31-43.

Tiernan, D., Zeleke, G., Owende, P. M. O., Kanali, C. L., Lyons, J. et al., 2004: Effect of working conditions on forwarder productivity in cut-to-length timber harvesting on sensitive forest sites in Ireland. Biosystems Engineering, 87:167-177.

Tsyvin, M. M., 1973: Ispol'zovanije drevesnoj kory. Moscow, Forest industry, $96 \mathrm{p}$.

Tufts, R.A, Brinker, R. W., 1993: Productivity of a Scandinavian system while second thinning pine plantations. Forest Products Journal, 43:24-32.

Tufts, R. A., 1997: Productivity and cost of the Ponsse 15-series, cut-to-length harvesting system in southern pine plantations. Forest Products Journal, 47:39-46.

Voinash, A. S., Vonash, S. A., 2011: Issledovanije vlijanija rejsovoj nagruzki na prochodimost' guseničnogo sortimentovoza. Forest Journal, 5:47-53.

Vossbrink, J., Horn, R., 2004: Modern forestry vehicles and their impact on soil physical properties. European Journal Forest Research, 123:259-267.

Wang, J., LeDoux, C. B., Yaoxiang, L., 2005: Simulating cut-to-length harvesting operations in Appalachian hardwoods. International Journal of Forest Engineering, 16:11-27. 